\title{
Neuromodulation in intractable pain management: outcomes and predictors of revisions of spinal cord stimulators
}

\author{
Shyamal C. Bir, MD, PhD, Subhas Konar, MCh, Tanmoy Maiti, MD, MCh, Anil Nanda, MD, MPH, and \\ Bharat Guthikonda, MD
}

Department of Neurosurgery, Louisiana State University Health-Shreveport, Louisiana

\begin{abstract}
OBJECTIVE Spinal cord stimulators (SCSs) appear to be safe and efficacious for chronic intractable back pain. Although there are many reports on percutaneous SCSs, there are very few studies on outcomes of paddle lead SCSs. In addition, the predictors of requirement for SCS revision have not been well established. Here, the authors review the outcome of a case series and attempt to identify the predictors of SCS revisions.
\end{abstract}

METHODS The clinical and radiological information of 141 patients with intractable chronic pain who underwent SCS implantation within the past 20 years was retrospectively reviewed. Paddle lead SCSs were used in this series. Statistical analysis was conducted using Kaplan-Meier curves and Cox proportional-hazards regression.

RESULTS Among 141 cases, 90 (64\%) did not require any revision after SCS implantations. Removal of the SCS was required in 14 patients. The average pain score was significantly reduced (preimplantation score of $8 \mathrm{vs} \mathrm{postimplantation}$ score of 1.38; $p<0.0001)$. Younger age, male sex, obesity, a preimplantation pain score $\geq 8$, and the presence of neuromuscular pain were identified as predictors of the overall requirement for SCS revision. However, only a preimplantation pain score $\geq 8$ was identified as a predictor of early failure of the SCS.

CONCLUSIONS Implantation of a paddle lead SCS is a relatively less invasive, safe, and effective procedure for patients with intractable back pain. Revision of the procedure depends on many factors, including younger age, male sex, associated neuromuscular pain, and severity of the pain. Therefore, patients with these factors, for whom implantation of an SCS is planned, should be closely followed for the possible requirement for revision.

http://thejns.org/doi/abs/10.3171/2016.3.FOCUS15634

KEY WORDS spinal cord stimulator; outcomes; complications; revision; predictors

$\mathrm{N}$ EUROMODULATION with a spinal cord stimulator (SCS; dorsal column stimulator) was first implemented in 1967 by Clyde Norman Shealy for the treatment of intractable pain. The complications of SCSs were initially due to poor patient selection and the mechanical disadvantage of the device. ${ }^{7,8}$ However, in the last 2 decades, outcomes of neuromodulation with the SCS have improved significantly due to technological advancements and better surgical techniques. In 1989, the FDA approved the use of SCSs for the management of chronic pain syndrome. ${ }^{6}$ Spinal cord stimulators are widely used and represent a potential alternative for the treatment of failed-back surgery syndrome (FBSS), complex regional pain syndrome, and radiculopathies refractory to conservative management. ${ }^{6-8}$ Although SCSs are less invasive, safe, and efficient for the management of intractable pain, immediate and long-term complications after SCS implantation are not uncommon. ${ }^{3,6,11,18}$ Any malfunction or nonfunction leads to revision or removal of the SCS, increasing the chances of additional surgery, prolonged hospital stay, and increased health care cost, and thereby decreased patient satisfaction..$^{12}$ In this study, we attempted to evaluate outcomes and complications of SCSs after implantation. We also established predictors of revision or removal of SCSs.

\section{Methods}

This study was performed after approval by the institutional review board at Louisiana State University Health 
TABLE 1. Demographic data of 141 patients with intractable chronic pain who underwent SCS implantation

\begin{tabular}{lc}
\hline \multicolumn{1}{c}{ Parameter } & Value $(\%)$ \\
\hline Total no. of patients & 141 \\
\hline Age, yrs & 59 \\
\hline Mean & $26-80$ \\
\hline Range & \\
\hline Sex & $68(48.2)$ \\
\hline M & $73(51.8)$ \\
\hline F & $121(85.6)$ \\
\hline Race & $20(14.2)$ \\
\hline White & $63(44.6)$ \\
\hline African American & $78(55.4)$ \\
\hline Indication & $8,7-9$ \\
\hline FBSS &
\end{tabular}

Sciences Center (Shreveport, LA). Information related to clinical history, neuroimaging, microsurgical dissection, and outcomes of the patients who underwent implantation of an SCS between January 2001 and June 2015 was collected retrospectively by review of each patient's case notes, follow-up chart, and radiology reports.

\section{Patient Selection}

\section{Demographic Data of Patients and Chronic Back Pain} Characteristics

A total of 141 patients with chronic back pain underwent implantation of a paddle lead SCS between 2001 and 2015. All cases underwent an initial trial using a percutaneous SCS before starting its use as a definitive treatment for chronic pain. In this series, the average age of patients was 59 years (range $26-80$ years). Of these 141 patients, $68(48.2 \%)$ were men and $73(51.8 \%)$ were women. One hundred twenty-one $(85.6 \%)$ of the patients were white and $20(14.2 \%)$ were African American. In this series, common indications for implantation of the SCS were FBSS and chronic back pain (e.g., lumbar neuropathy, sciatica) with failure of conservative management. The mean preimplantation pain score was 8 (range 7-9) (Table 1).

\section{Procedure for SCS Implantation}

We recruited patients for permanent placement of leads after completion of a successful trial with a percutaneous SCS to avoid spinal surgery. The results of the trial determined the number of leads, electrodes, and proper placement of leads for pain coverage. The patient was placed prone with proper protection of pressure points. With the help of a fluoroscope, the pedicle of the targeted spinal segment was marked. The skin over the entry zone was prepared with antiseptic solution and draped. The senior author (B.G.) preferred the left paramedian incision. A mini-laminectomy was performed using a standard approach. Flavectomy and minimal resection of superior and inferior lamina was performed to create a space for the paddle lead. A paddle lead was then placed in the median position, with tunneling of 2 extension cables through the left paramedian space. Later, the cables were connected with implanted pulse generators in the left subcutaneous area. The final position of the lead was confirmed with fluoroscopy (Figs. 1 and 2).

\section{Patient Follow-Up}

Preoperative and follow-up data were collected from the study population. Radiographs of the thoracolumbar region were obtained at 3-month intervals during the 1st year after placement of the SCS and at 6-month intervals for subsequent years. The median duration of follow-up was 31.49 months (3-166 months).

\section{Statistical Analysis}

Commercially available software, SPSS version 21.0 (SPSS, Inc.), was used for statistical analysis. The KaplanMeier method of survival analysis was used to estimate revision-free survival (RFS). The log-rank (Mantel-Cox) test was used to analyze the survival difference in the
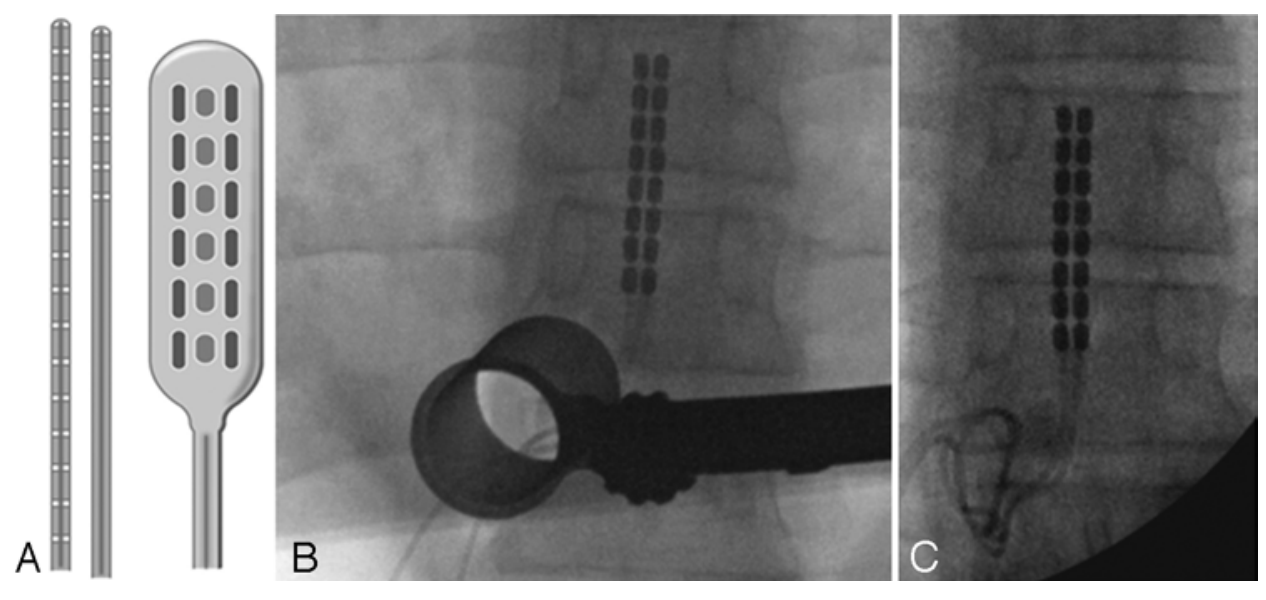

FIG. 1. A: Images of the percutaneous (left) and paddle lead (right) SCS. Copyright Medical Communications, Louisiana State University Health Sciences Center-Shreveport. Published with permission. B: Illustration of electrode installation. C: The electrode in its final position. 

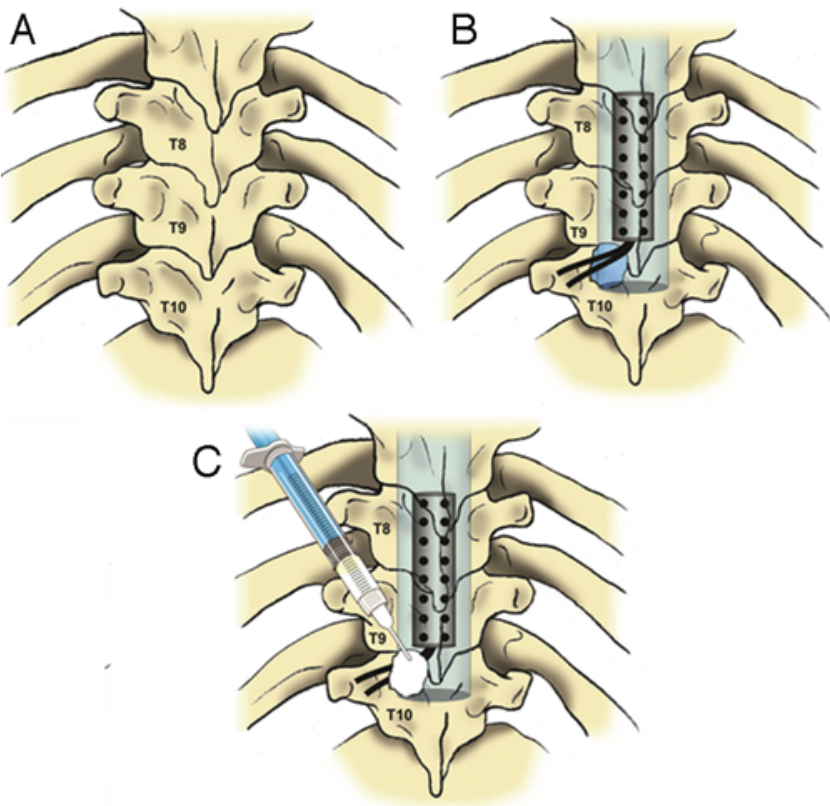

FIG. 2. Steps of the procedure. A: A portion of the lamina of the spinal segment is removed to create a window through which the electrode is inserted. B: The electrode is placed and its functionality is verified. C: The window is sealed with bone cement. Copyright Medical Communications, Louisiana State University Health Sciences Center-Shreveport. Published with permission.

cases. A Cox proportional hazards regression model was used to determine independent significant factors for RFS. When necessary, the chi-square test was used. A p value $<$ 0.05 was considered significant.

\section{Results}

The mean preimplantation pain score was 8 (range 7-9). There was no significant difference in mean preimplantation pain score between groups. However, the mean pain score at last follow-up was 1.38 (range $0-7$ ). There was a significant difference between mean pre- and postimplantation pain scores between groups (Table 2).

Ninety cases $(64 \%)$ did not require any further intervention; for 14 patients, removal of the SCS was required. Among these 14 patients, 9 did not need the SCS anymore because they no longer experienced substantial pain. However, 5 patients required a different surgical intervention (laminectomy) to control the pain. Forty-six patients (32.6\%) underwent SCS revision for several reasons (Table 3).

\section{Causes of SCS Revision}

The leading causes of revision were hardware-related problems (nonfunction/malfunction), followed by infection and migration of the lead. The median time to revision was 25.37 months (range 3-145 months; Table 3).

\section{Revision-Free Survival Outcome}

The overall median RFS was 43 months. The RFS rate after 1,3 , and 5 years was $75 \%, 65 \%$, and $45 \%$, respectively (Fig. 3).

\section{Effect of Age on RFS}

The median RFS for patients $\geq 60$ years was 56 months, and in patients $<60$ years it was 38 months. This difference in the median RFS between the 2 groups reached statistical significance $(\log -$ rank $\mathrm{p}=0.02)($ Fig. $4 \mathrm{~A})$.

\section{Effect of Male or Female Sex on RFS}

The median RFS for men was 25 months, and in women it was 43 months. This difference in the median RFS between the 2 groups reached statistical significance (logrank $\mathrm{p}=0.03$ ) (Fig. 4B).

\section{Effect of Race on RFS}

The median RFS for white patients was 38 months, and for African American patients it was 34 months. This dif-

TABLE 2. Pain score before and after SCS implantation

\begin{tabular}{|c|c|c|c|}
\hline Variable & $\begin{array}{l}\text { Preimplantation Pain Score } \\
\text { (range) }\end{array}$ & $\begin{array}{l}\text { Pain Score at Recent Follow-Up } \\
\text { (range) }\end{array}$ & p Value* \\
\hline \multicolumn{4}{|l|}{ Indication } \\
\hline FBSS & $8.23(7-9)$ & $1.6(0-7)$ & 0.001 \\
\hline $\begin{array}{l}\text { Chronic back pain w/ failure of conservative } \\
\text { management }\end{array}$ & $8.31(7-9)$ & $1.15(0-8)$ & $<0.01$ \\
\hline \multicolumn{4}{|l|}{ Follow-up } \\
\hline No intervention & $8.09(7-9)$ & $1.13(0-3)$ & $<0.0001$ \\
\hline Revision & $8.10(7-9)$ & $1.23(0-6)$ & $<0.01$ \\
\hline Surgery/laminectomy & $8.46(7-9)$ & $3.53(0-8)$ & $<0.01$ \\
\hline \multicolumn{4}{|l|}{ Sex } \\
\hline M & $8.19(7-9)$ & $1.34(0-8)$ & $<0.0001$ \\
\hline $\mathrm{F}$ & $8.32(7-9)$ & $1.42(0-7)$ & $<0.0001$ \\
\hline \multicolumn{4}{|l|}{ Race } \\
\hline African American & $8.15(7-9)$ & $1.10(0-7)$ & 0.001 \\
\hline White & $8.28(7-9)$ & $1.42(0-8)$ & $<0.0001$ \\
\hline
\end{tabular}

\footnotetext{
* A p value $<0.05$ is considered significant.
} 
TABLE 3. Follow-up results after SCS implantation

\begin{tabular}{lc}
\hline \multicolumn{1}{c}{ Variable } & Value (\%) \\
\hline Mean follow-up in mos, range & $31.49,3-166$ \\
\hline No further intervention & $90(63.8)$ \\
\hline Removal & $14(9.9)$ \\
\hline No revision required & $9(6.4)$ \\
\hline Required different surgery, i.e., laminectomy & $5(3.5)$ \\
\hline SCS revision & $46(32.6)$ \\
\hline Cause of revision & \\
\hline$\quad$ Nonfunction & $28(19.8)$ \\
\hline$\quad$ Malfunction & $11(7.8)$ \\
\hline$\quad$ Migration of lead & $3(2.1)$ \\
\hline Infection & $4(2.8)$ \\
\hline Follow-up & $5(2.4)$ \\
\hline Early revision, <6 mos & $25.37,3-145$ \\
\hline Median no. of mos to revision, range
\end{tabular}

ference in the median RFS between the 2 groups did not reach statistical significance (log-rank $\mathrm{p}=0.30)$ (Fig. 4C).

\section{Effect of Obesity on RFS}

The median RFS for patients with a body mass index $(\mathrm{BMI}) \geq 30 \mathrm{~kg} / \mathrm{m}^{2}$ was 25 months, and for patients with a BMI $<30 \mathrm{~kg} / \mathrm{m}^{2}$ it was 41 months. This difference in the median RFS between the 2 groups achieved statistical significance $(\log$-rank $\mathrm{p}=0.03)$ (Fig. 5 left).

\section{Effect of Diabetes Mellitus on RFS}

The median RFS in patients with diabetes mellitus (DM) was 35 months, and in patients without DM it was 43 months. This difference in the median RFS between

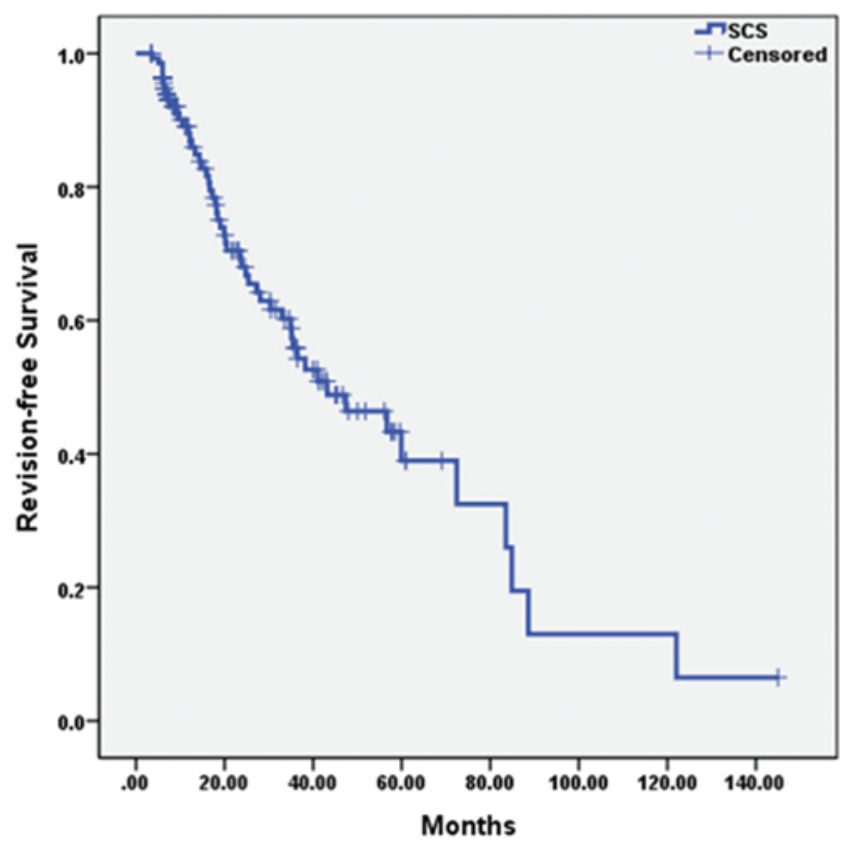

FIG. 3. Overall RFS of patients who underwent SCS implantation. the 2 groups did not reach statistical significance (log-rank $\mathrm{p}=0.98$ ) (Fig. 5 right).

\section{Effect of Preimplantation Pain Score on RFS}

The median RFS in patients with a pain score $<8$ was 59 months, and in patients with a pain score $\geq 8$ it was 33 months. This difference in the median RFS between the 2 groups reached statistical significance $(\log$-rank $\mathrm{p}=0.02)$ (Fig. 6A).

\section{Effect of Neuromuscular Pain on RFS}

The median RFS in patients with neuromuscular pain (mostly fibromyalgia) was 18 months, and in patients without neuromuscular pain it was 59 months. This difference in the median RFS between the 2 groups reached statistical significance (log-rank p < 0.0001) (Fig. 6B).

\section{Effect of Depression on RFS}

The median RFS in patients with depression was 34 months, and in patients without depression it was 56 months. This difference in the median RFS between the 2 groups did not reach statistical significance (log-rank $\mathrm{p}$ $=0.22)($ Fig. 6C).

\section{Outcomes During Early Follow-Up ( $<6$ Months) After Implantation of SCS}

The median RFS during early follow-up was 5.6 months (range 3.4-5.8 months). In this series, 5 cases (2.4\%) required revision within 6 months of initial SCS implantation (Table 3).

\section{Factors for Revisions Required Within First 6 Months of SCS Implantation}

Preimplantation Pain Score

The median RFS in patients with a pain score $<8$ was 6 months, and in patients with a pain score $\geq 8$ it was 4 months. This difference in the median RFS between the 2 groups reached statistical significance $(\log$-rank $\mathrm{p}=$ 0.005) (Fig. 7A).

\section{Obesity/Higher BMI}

The median RFS in patients with a BMI $\geq 30 \mathrm{~kg} / \mathrm{m}^{2}$ was 5 months, and in patients with a BMI $<30 \mathrm{~kg} / \mathrm{m}^{2}$ it was 6 months. This difference in the median RFS between the 2 groups did not reach statistical significance (log-rank $\mathrm{p}=0.12)$ (Fig. 7B).

\section{Neuromuscular Pain}

The median RFS in patients with neuromuscular pain (mostly fibromyalgia) was 5 months, and in patients without neuromuscular pain it was 6 months. This difference in the median RFS between the 2 groups did not reach statistical significance (log-rank $\mathrm{p}=0.09)($ Fig. 7C).

\section{Factors Predictive of Required Revision After SCS Implantation}

Cox regression was performed to identify the predictors of revision in patients who underwent SCS implantation; the results are shown in Tables 4 and 5. The following 
A

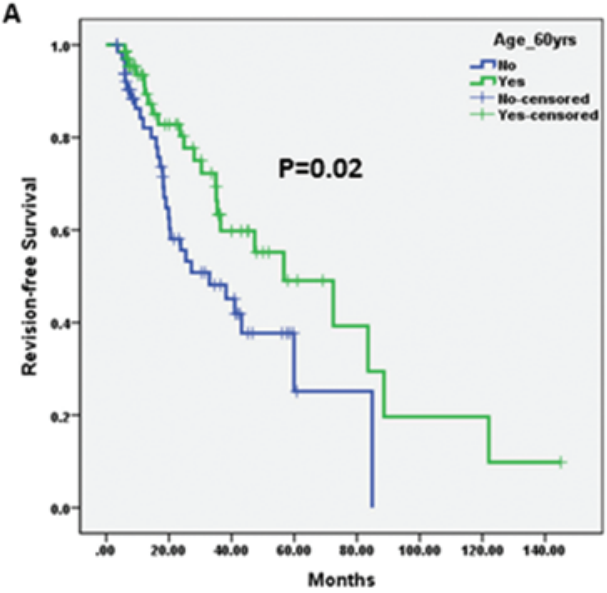

B



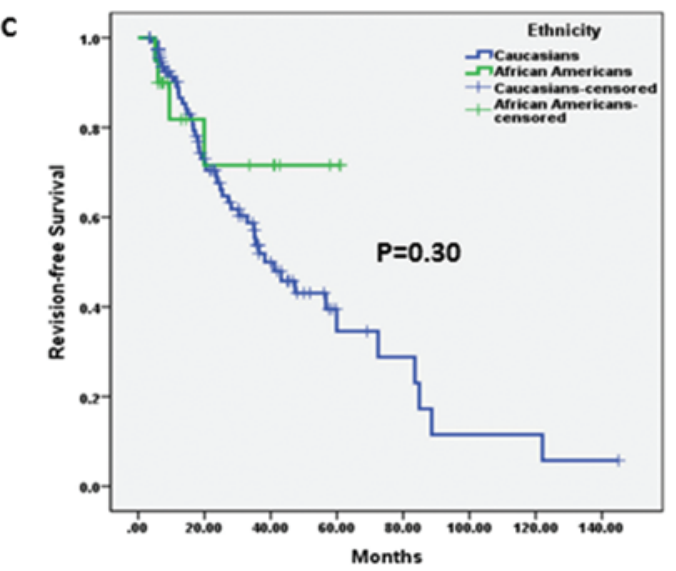

FIG. 4. A: Comparison of RFS based on age of patients. B: Comparison of RFS based on sex of patients. C: Comparison of RFS based on race of patients. A p value $<0.05$ is considered significant.

covariates were included in the model: age $(\geq 60$ years vs $<60$ years), sex (male vs female), race (white vs African American), obesity (yes vs no), DM (yes vs no), preimplantation pain score $(\geq 8$ vs $<8$ ), neuromuscular pain (yes vs no), and depression (yes vs no). Among the listed factors, age $<60$ years, male sex, obesity, neuromuscular pain, and a preimplantation pain score $\geq 8$ were identified as predictors of earlier requirement for revisions. In multivariate analysis, age $<60$ years, male sex, and neuromuscular pain were revealed as predictors of shorter RFS. However, race, depression, and DM did not show any significant relationships with revisions in this study. In an earlier outcome study, we determined the predictors (obesity, preimplantation pain, and neuromuscular pain) of SCS revision. However, in univariate and multivariate analyses, only a preimplantation pain score $\geq 8$ was identified as a predictor of early failure of SCS implantation.

\section{Discussion}

The clinical use of SCSs for chronic severe pain has been increasing due to better safety, efficacy, and costeffectiveness. ${ }^{6,16}$ Significant advancements of hardware, programming algorithms, anchoring options, and surgical techniques have minimized complications and requirements for revisions of SCSs. ${ }^{13,16,19}$ However, despite this improvement, the requirement for SCS revision is not uncommon. ${ }^{13}$ In this series, we investigated the outcomes of SCS implantation as treatment for intractable back pain and we established the predictors of requirements for early and late revisions.

\section{Pain Relief}

One objective of this study was to evaluate pain relief after SCS implantation. In our series, there was significant relief of pain after SCS implantation, which is consistent with the previous study by Matias et al. ${ }^{13}$ The average decrease in pain score was more than 6 points. The degree of pain relief was associated with the indication for revision of SCS or spine surgery such as laminectomy.

\section{Complications and Requirements for Early and Late SCS Revision}

Although SCS implantation is an efficacious treatment for intractable pain, it is not without complications. In our series, the complications rate was $36 \%$, which is consistent with the findings of earlier studies with ranges from $31.6 \%$ to $54.6 \%$.6,14,22 The most common indications for revision were nonfunction or malfunction of the hardware, migration of the lead, and infection. In this series, more than $50 \%$ of revision cases required revisions due to nonfunc- 

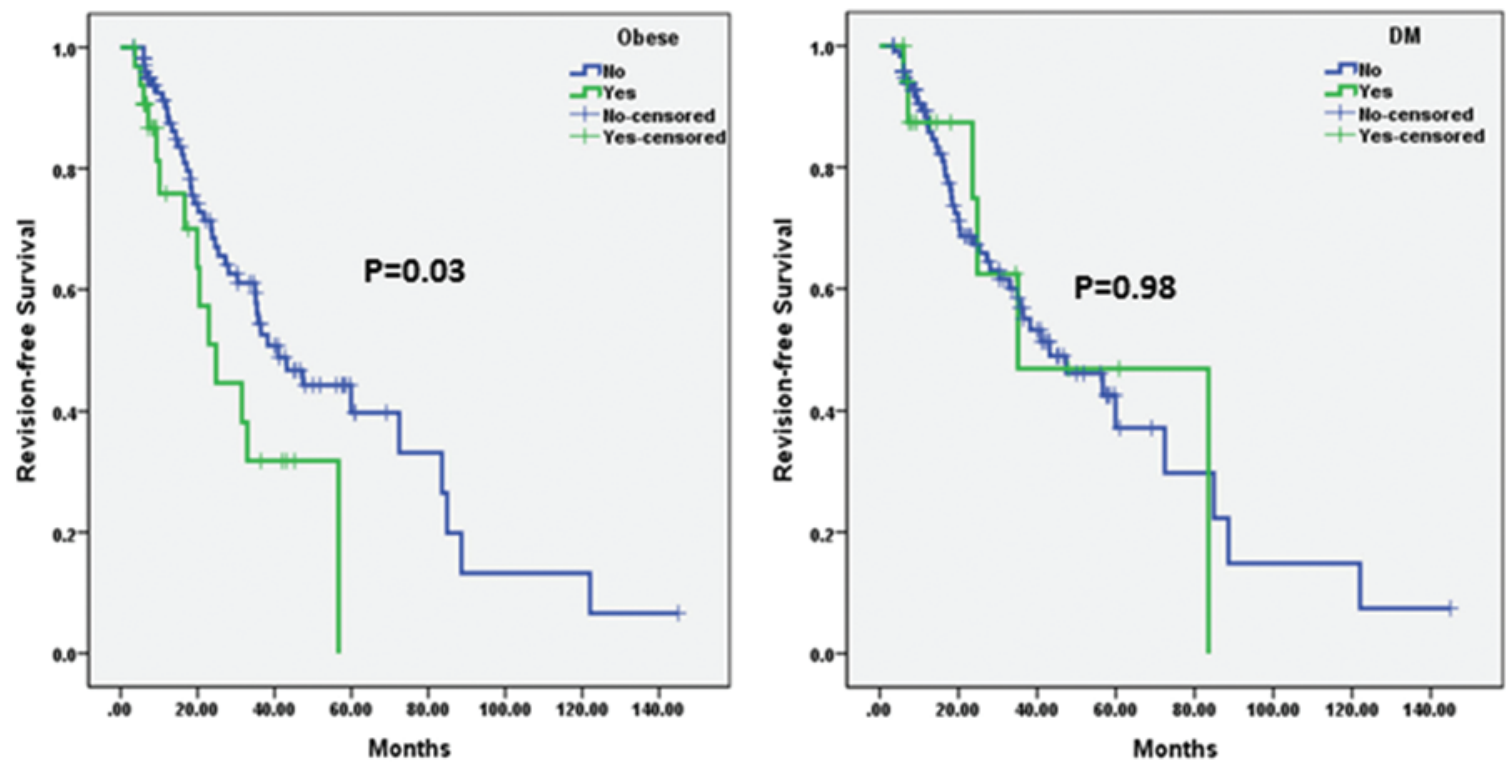

FIG. 5. Left: Comparison of RFS based on whether or not patient is obese. Right: Comparison of RFS based on whether or not patient is diabetic. A p value $<0.05$ is considered significant.

A



B

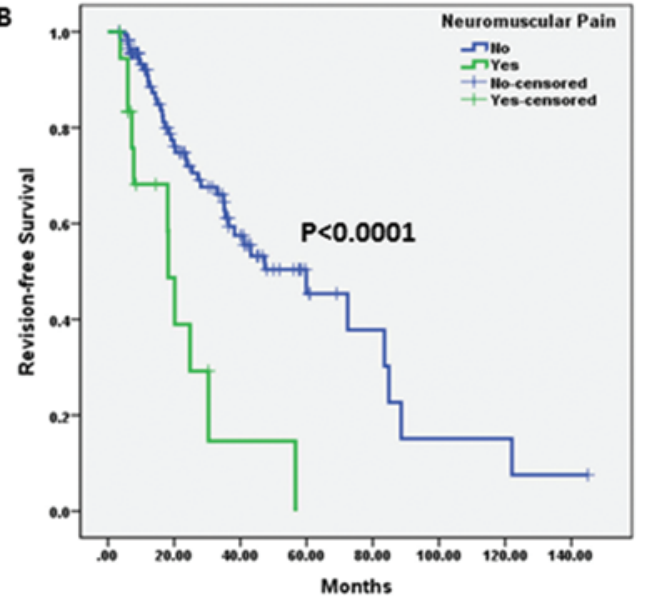



FIG. 6. A: Comparison of RFS based on severity of pain. B: Comparison of RFS based on presence or absence of neuromuscular pain. C: Comparison of RFS based on patients with or without depression. A p value $<0.05$ is considered significant. 




B



C



FIG. 7. Revision-free survival within 6 months of SCS implantation. A: Comparison of RFS based on severity of pain. B: Comparison of RFS based on whether or not patient is obese. C: Comparison of RFS based on presence or absence of neuromuscular pain. A $p$ value $<0.05$ is considered significant.

tion of the SCS hardware, and this result is in agreement with the findings of previous reports. ${ }^{6,14,22}$ Surprisingly, the percentage $(2.1 \%)$ of lead migration was comparatively lower than that in an earlier report. ${ }^{6}$

This finding can be explained by the following factors. 1) The use of paddle leads in all cases of our series. ${ }^{13}$ 2) Improvement in the delivery of stimulators over time, be-

\section{TABLE 4. Univariate Cox regression analysis for predictors of} SCS revision

\begin{tabular}{lll}
\hline \multicolumn{1}{c}{ Variable } & $\mathrm{HR}(95 \% \mathrm{Cl})$ & $\mathrm{p} \mathrm{Value}$ \\
\hline Last follow-up & & \\
\hline Age, $\geq 60$ vs <60 yrs & $0.53(0.30-0.94)$ & 0.02 \\
\hline Sex, F vs M & $0.57(0.33-0.97)$ & 0.03 \\
\hline Race, white vs African American & $0.59(0.21-10.64)$ & 0.30 \\
\hline Obesity, yes vs no & $1.91(1.05-3.54)$ & 0.03 \\
\hline DM, yes vs no & $1.00(0.42-2.36)$ & 0.98 \\
\hline Pain score, $\geq 8$ vs <8 & $0.54(0.32-0.94)$ & 0.02 \\
\hline Neuromuscular pain, yes vs no & $3.26(1.66-6.40)$ & 0.001 \\
\hline Depression, yes vs no & $1.47(0.78-1.77)$ & 0.232 \\
\hline Early follow-up, $<6$ mos & & \\
\hline Obesity, yes vs no & $3.52(0.58-21.16)$ & 0.17 \\
\hline Pain score, $\geq 8$ vs <8 & $0.54(0.32-0.94)$ & 0.007 \\
\hline Neuromuscular pain, yes vs no & $3.87(0.64-23.20)$ & 0.14 \\
\hline
\end{tabular}

* A p value $<0.05$ is considered significant. cause the revision rate decreased with more experience of the surgeons and higher familiarity with SCSs. In this series, the revision rate was 53\% in earlier cases (before 2011 ) and $29 \%$ in later cases (during or after 2011) ( $\mathrm{p}=$ 0.007). 3) Advancement in surgical technique, including better anchoring of the SCS, which in turn may represent a trend toward a decreased incidence of lead migration. ${ }^{6}$

Infection was the biological complication in our series, with a rate of $2.8 \%$. This finding is comparable to results in the literature, with reported ranges of 3.4\%-8.6\% . . $9,14,21,22^{2}$ In our series, no patient experienced meningitis, and infections were managed by removal of the SCS and intravenous antibiotics.

TABLE 5. Multivariate Cox regression analysis for predictors of SCS revision

\begin{tabular}{lll}
\hline \multicolumn{1}{c}{ Variable } & HR $(95 \% \mathrm{Cl})$ & $\mathrm{p} \mathrm{Value}$ \\
\hline Last follow-up & & \\
\hline Age, $\geq 60$ vs $<60$ yrs & $0.79(1.03-3.09)$ & 0.036 \\
\hline Sex, F vs M & $1.99(1.14-3.51)$ & 0.016 \\
\hline Obesity, yes vs no & $0.73(0.39-1.36)$ & 0.32 \\
\hline Pain score, $\geq 8$ vs $<8$ & $0.61(0.35-1.05)$ & 0.07 \\
\hline Neuromuscular pain, yes vs no & $0.30(0.14-0.61)$ & 0.001 \\
\hline Early follow-up, $<6$ mos & & \\
\hline Pain score, $\geq 8$ vs $<8$ & $0.95(0.07-2.97)$ & 0.008 \\
\hline
\end{tabular}

* A p value $<0.05$ is considered significant. 


\section{Revision Timeline}

As would be expected, earlier revisions were performed among patients who developed infections after implantation. The median time to revision among these patients was 5.6 months, which is shorter compared with the time to revision for hardware-related complications. ${ }^{6}$ In our series, the median time to revision for hardware-related complications (e.g., nonfunction) was 23 months, but loss of functional activity of the SCS could occur at any time (range 5-122 months). The causal factor of hardware-related complications is not well established in the literature, and further investigation is needed on the long-term efficacy of SCS implantation. ${ }^{6}$

In this series, $40 \%$ of revisions were among patients with FBSS, and this is consistent with the previous report by Sears et al. ${ }^{20}$ There were 30 patients $(21 \%)$ with axial back pain and 111 patients $(79 \%)$ with neuropathic pain. Among patients with axial back pain, $50 \%$ of cases required revision. However, among patients with neuropathic pain, only $34 \%$ of cases required revision. . $^{2,5,6,10,15,17}$ In addition, in this study, the median RFS was 28 and 47 months for axial back pain and neuropathic pain, respectively ( $\mathrm{p}=0.39$; Fig. 8$)$.

Previous studies showed that based on SCS type, requirements for revision and complications varied. ${ }^{6,20} \mathrm{Be}-$ cause we performed paddle lead SCS implantation after confirming the efficacy with percutaneous SCS implantation, it is difficult to compare the efficacy and complications of these 2 types of hardware. However, an earlier report $^{1}$ showed that the overall ( $>5$ years) reoperation rate was approximately 3 times higher in percutaneous lead SCS implantation (22.9\% vs $8.5 \%$ ). The complication rate was slightly higher in paddle lead SCS implantation (3.4\% vs $2.2 \%$ ).

In addition, patients who received percutaneous lead SCS implantation (which cost $\$ 30,200$ ) had higher hospitalization costs than those who underwent paddle lead SCS implantation (which cost \$29,963). One- and 2-year outpatient use and costs were significantly higher in the percutaneous lead SCS implantation group $(\$ 50,793)$ compared with the paddle lead SCS implantation group $(\$ 37,147)$.

\section{Predictors of SCS Revision}

On the basis of the literature, predictors of requirement for SCS revision are not well established. Recently, De La Cruz et al. showed that drug use and active smoking were positive predictors of early SCS revision. ${ }^{4}$ In the present study, we attempted to identify the predictors of both early and overall revision of SCS. Our results did not reveal smoking $(p=0.24)$ and drug use $(p=0.41)$ as predictors of SCS revision. The discrepancy of results may be due to fewer smokers (nonsmokers, $\mathrm{n}=108$ vs smokers, $\mathrm{n}=$ 33 ) and drug users (nondrug users, $\mathrm{n}=124$ vs drug users, $\mathrm{n}=17$ ) in our cohort. However, our results revealed that patients of younger age and male sex had a higher rate of revision compared with patients who were older and female. This finding can be explained by the active lifestyle and increased outdoor activities of a young male population (i.e., greater movement leads to a higher rate of lead migration) However, as would be suspected, there was no



FIG. 8. Comparison of RFS after implantation of paddle lead SCS based on type of pain (neuropathic vs axial low-back pain). A p value $<0.05$ is considered significant.

significant difference in the revision rate between races (white vs African American). Obese patients required more revisions than lean patients, but there was no significant difference in revision rates between patients with or without DM. In addition, patients with either a preimplantation pain score $\geq 8$ or neuromuscular pain had higher rates of revision. This can be explained by the severity of local pain or local pain associated with muscular pain, either of which might have contributed to the requirement for more revisions in these cases. In this series, the failure of SCS implantation in patients with intractable low-back pain with neuromuscular pain (fibromyalgia) was due to either malfunction or nonfunction of the SCS. However, psychological factors might have also contributed to the SCS failure in these patients. Similarly, we also determined the predictor of requirement for early revision of SCS and found that a preimplantation pain score $\geq 8$ was a positive predictor of early revision. However, there was no significant difference in revision rates between patients with or without depression.

\section{Limitations of the Study}

The present study has several limitations due to its retrospective nature. The SCS implantations were performed by various surgeons with different levels of surgical expertise, although most of the surgeries were performed by the senior author (B.G.).

\section{Conclusions}

Implantation of paddle lead SCS is a relatively less invasive procedure (compared with traditional spinal surgery [e.g., laminectomy]) that is safe and effective for patients with intractable back pain. Revision of the procedure de- 
pends on several factors, including younger age, male sex, associated neuromuscular pain, and severity of the pain. Therefore, patients with these factors who undergo SCS implantation should be closely followed for the possible requirement for revision. However, a randomized controlled trial in a large number of patients with intractable pain should be pursued to improve overall management or decrease the requirement for revision, identify the predictors of revision, and improve the quality of life of patients.

\section{References}

1. Babu R, Hazzard MA, Huang KT, Ugiliweneza B, Patil CG, Boakye M, et al: Outcomes of percutaneous and paddle lead implantation for spinal cord stimulation: a comparative analysis of complications, reoperation rates, and health-care costs. Neuromodulation 16:418-427, 2013

2. Barolat G, Oakley JC, Law JD, North RB, Ketcik B, Sharan A: Epidural spinal cord stimulation with a multiple electrode paddle lead is effective in treating intractable low back pain. Neuromodulation 4:59-66, 2001

3. Cameron T: Safety and efficacy of spinal cord stimulation for the treatment of chronic pain: a 20 -year literature review. J Neurosurg 100 (3 Suppl Spine):254-267, 2004

4. De La Cruz P, Fama C, Roth S, Haller J, Wilock M, Lange S, et al: Predictors of spinal cord stimulation success. Neuromodulation 18:599-602, 2015

5. Harke H, Gretenkort P, Ladleif HU, Rahman S: Spinal cord stimulation in sympathetically maintained complex regional pain syndrome type I with severe disability. A prospective clinical study. Eur J Pain 9:363-373, 2005

6. Hayek SM, Veizi E, Hanes M: Treatment-limiting complications of percutaneous spinal cord stimulator implants: a review of eight years of experience from an academic center database. Neuromodulation 18:603-609, 2015

7. Jeon Y, Huh BK: Spinal cord stimulation for chronic pain. Ann Acad Med Singapore 38:998-1003, 2009

8. Jeon YH: Spinal cord stimulation in pain management: a review. Korean J Pain 25:143-150, 2012

9. Kay AD, McIntyre MD, Macrae WA, Varma TR: Spinal cord stimulation-a long-term evaluation in patients with chronic pain. Br J Neurosurg 15:335-341, 2001

10. Kemler MA, De Vet HC, Barendse GA, Van Den Wildenberg FA, Van Kleef M: The effect of spinal cord stimulation in patients with chronic reflex sympathetic dystrophy: two years' follow-up of the randomized controlled trial. Ann Neurol 55:13-18, 2004

11. Kumar K, Buchser E, Linderoth B, Meglio M, Van Buyten JP: Avoiding complications from spinal cord stimulation: practical recommendations from an international panel of experts. Neuromodulation 10:24-33, 2007

12. Kumar K, Wilson JR, Taylor RS, Gupta S: Complications of spinal cord stimulation, suggestions to improve outcome, and financial impact. J Neurosurg Spine 5:191-203, 2006

13. Matias CM, Amit A, Lempka SF, Ozinga JG IV, Nagel SJ, Lobel DA, et al: Long-term outcomes after replacement of percutaneous leads with paddle leads in a retrospective co- hort of patients with spinal cord stimulation systems. Neurosurgery 75:430-436, 2014

14. Mekhail NA, Mathews M, Nageeb F, Guirguis M, Mekhail MN, Cheng J: Retrospective review of 707 cases of spinal cord stimulation: indications and complications. Pain Pract 11:148-153, 2011

15. North RB, Kidd DH, Olin J, Sieracki JM, Farrokhi F, Petrucci L, et al: Spinal cord stimulation for axial low back pain: a prospective, controlled trial comparing dual with single percutaneous electrodes. Spine (Phila Pa 1976) 30:1412-1418, 2005

16. North RB, Kidd DH, Olin JC, Sieracki JM: Spinal cord stimulation electrode design: prospective, randomized, controlled trial comparing percutaneous and laminectomy electrodespart I: technical outcomes. Neurosurgery 51:381-390, 2002

17. Oakley JC, Weiner RL: Spinal cord stimulation for complex regional pain syndrome: a prospective study of 19 patients at two centers. Neuromodulation 2:47-50, 1999

18. Rosenow JM, Stanton-Hicks M, Rezai AR, Henderson JM: Failure modes of spinal cord stimulation hardware. J Neurosurg Spine 5:183-190, 2006

19. Sankarasubramanian V, Buitenweg JR, Holsheimer J, Veltink PH: Staggered transverse tripoles with quadripolar lateral anodes using percutaneous and surgical leads in spinal cord stimulation. Neurosurgery 72:483-491, 2013

20. Sears NC, Machado AG, Nagel SJ, Deogaonkar M, StantonHicks M, Rezai AR, et al: Long-term outcomes of spinal cord stimulation with paddle leads in the treatment of complex regional pain syndrome and failed back surgery syndrome. Neuromodulation 14:312-318, 2011

21. Turner JA, Loeser JD, Bell KG: Spinal cord stimulation for chronic low back pain: a systematic literature synthesis. Neurosurgery 37:1088-1096, 1995

22. Turner JA, Loeser JD, Deyo RA, Sanders SB: Spinal cord stimulation for patients with failed back surgery syndrome or complex regional pain syndrome: a systematic review of effectiveness and complications. Pain 108:137-147, 2004

\section{Disclosures}

The authors report no conflict of interest concerning the materials or methods used in this study or the findings specified in this paper.

\section{Author Contributions}

Conception and design: Guthikonda, Bir, Konar, Maiti. Acquisition of data: Bir. Analysis and interpretation of data: Bir, Konar, Maiti. Drafting the article: Bir, Konar, Maiti. Critically revising the article: all authors. Reviewed submitted version of manuscript: Guthikonda, Nanda. Approved the final version of the manuscript on behalf of all authors: Guthikonda. Administrative/ technical/material support: Guthikonda, Nanda. Study supervision: Guthikonda, Nanda.

\section{Correspondence}

Bharat Guthikonda, Department of Neurosurgery, Louisiana State University Health-Shreveport, 1501 Kings Hwy., Shreveport, LA 71103-33932.email: bguthi@1suhsc.edu. 